\title{
ANALISIS PENDIDIKAN DARAH WANITA DALAM KURIKULUM RENDAH DAN MENENGAH DI MALAYSIA
}

\author{
Siti Fatimah Binti Salleh ${ }^{1}$ \\ Zurita Binti Mohd Yusuff \\ Siti Khatijah Binti Ismail \\ Nadhirah Binti Nordin \\ Tengku Fatimah Muliana Binti Tengku Muda \\ Ramlah Binti Mat Ali \\ Universiti Sultan Zainal Abidin, Malaysia
}

\begin{abstract}
Abstrak: Pendidikan darah wanita merupakan korpus ilmu yang wajib dikuasai oleh setiap muslim lelaki dan perempuan. Ulama silam telah memperakui kesukaran menguasai ilmu tentang darah wanita. Rentetan itu, berlaku pengamalan bervariasi yang menyebabkan berlaku silap faham masyarakat terhadap kaedah penentuan darah wanita. Hal ini menuntut kepada satu analisis tentang pendidikan darah wanita dalam kurikulum pendidikan Islam rendah dan menengah, ia menjadi objektif utama kepada kertas kerja ini dan mengenalpasti ilmu asas darah wanita yang perlu diutamakan sebagai pendidikan awal darah wanita kepada pelajar. Kajian ini menggunakan kaedah kepustakaan dengan menganalisis kandungan buku teks pendidikan Islam rendah dan menengah, teks kelasik dalam bidang fiqh, tafsir, hadis dan bahasa. Selain itu, kaedah pemerhatian kefahaman peserta kelas belia dan dewasa, bagi kelas pengajian darah wanita berasaskan soalan yang diajukan oleh peserta tentang status darah wanita. Kajian mendapati, silibus berkaitan pendidikan ilmu darah wanita dalam kurikulum pendidikan Islam samaada di peringkat rendah atau menengah di Malaysia hanya terbatas kepada konotasi sahaja iaitu haid, nifas, istihadhah dan wiladah. Tiada perbincangan hukum secara khusus kecuali disebut secara tidak langsung dalam topik perbincangan puasa dan mandi. Pembelajaran secara tidak berfokus memberi implikasi kepada tahap pemahaman dan usia pelajar mempelajari tentang hukum hakam darah wanita yang bervariasi ekoran tiada keselarasan skop dan tempoh pembelajaran.
\end{abstract}

Kata Kunci: analisis pendidikan, darah wanita, kurikuulum rendah dan menengah

\footnotetext{
${ }^{1}$ Maklumat penulis utama: Dr. Siti Fatimah Salleh, Pusat Pengajian Syariah, Fakulti Pengajian Kontemporari Islam, Universiti Sultan Zainal Abidin (UniSZA), Kampus Gong Badak,21300, Kuala Nerus, Terengganu, Malaysia. E-Mail: sitifatimah@unisza.edu.my
} 


\section{PENDAHULUAN}

I lmu darah wanita merupakan sub perbincangan di bawah bab ibadat. Kualiti ibadat sesorang manusia mukallaf diukur melalui tahap proses taharah yang sempurna. Ibadat merupakan tunjang asas kepada nilai kepatuhan hamba kepada Penciptanya. Tanpa kesempurnaan ibadat, tiada manfaat duniawi dan ukhrawi dalam jiwa seorang muslim. Bagi menjamin kualiti ibadat seseorang wanita, ia mempunyai perkaitan tentang proses pembelajaran dan individu yang wajib mempelajari. Aspek proses pembelajaran menjadi wajib dan fardu ain kerana isu ini berkait dengan kesahan ibadat secara fardi yang melibatkan pelbagai cakupan ibadat seperti wudhuk, solat, puasa, iktikaf, membaca al-Quran, memegang al-Quran, menulis al-Quran dan mengajar al-Quran. Oleh kerana pembelajaran ilmu darah wanita juga melibatkan cakupan individu yang wajib mempelajari iaitu tidak terbatas kepada kaum wanita sahaja, bahkan kewajipan mempelajari ilmu ini menjadi keutamaan kepada kaum lelaki kerana beban tanggungjawab yang digalas adalah mengajar ilmu fardhu ain kepada anak-anak perempuan bagi seorang bapa, kewajipan mengajar isteri bagi seorang lelaki yang bergelar suami dan kewajipan mengajar masyakat dan murid, bagi seorang guru atau pengajar. Kedudukan tanggungjawab mem- pelajari ilmu darah wanita ini saling berkaitan dan perlu digalas bersama kerana setiap individu mempunyai beban tanggung jawab serta peranan dan di pihak wanita pula sebagai pengaplikasi segala teori ilmu untuk menyelasaikan tuntutan ibadat setiap diri sendiri.

Berasaskan penelitian ikut serta pengkaji dengan peserta kelas-kelas pengajian dewasa dan pelajar sekolah rendah dan menengah tentang darah wanita, berlaku salah faham tentang warna darah, bilangan warna darah, pengiraan 15 hari maksimum suci, penentuan haid bagi kes istihadhah, salah faham menghitung hari-hari nifas dengan fahaman darah nifas mesti cukup 60 hari menurut mazhab Syafi'i, salah faham pengiraan permulaan suci adakah dengan bermula selepas 15 hari darah haid atau bermula selepas bersih daripada darah dalam tempoh tidak melebihi had maksimum haid.

Selain itu, berlaku juga kekeliruan dalam penggunaan konsep 'adah untuk darah yang seterusnya, kedudukan mandi wajib untuk suci dari haid dan junub dari segi aplikasinya serta kekeliruan yang ketara berkaitan mandi wiladah. Justeru, kajian mendapati perlu kepada analisis kandungan silibus pengajaran dan pembelajaran di peringkat rendah dan menengah bagi mengenalpasti aspek atau elemen fiqh yang berkait dengan darah wanita diterapkan di awal usia baligh kanak-kanak. 
Menurut hasil kajian oleh Noraini Ismail tentang Kefahaman Pelajar Terhadap Fiqh Thaharah (Permasalahan Darah Wanita) : Tinjauan Di Uitm Cawangan Perlis menunjukkan terdapat pelajar yang masih keliru untuk membezakan antara darah haid dan istihadhah. Mereka juga tidak memahami kaedah pengiraan tempoh suci dan tempoh haid. Keadaan ini telah menjejaskan tahap keyakinan mereka dalam menunaikan ibadah (https://world confe rences.net/proceedings/icasic2016)

Berdasarkan hasil kajian ini, penyelidik mencadangkan agar guru-guru, pensyarah dan semua yang terlibat dalam pendidikan khususnya bidang Pendidikan Islam agar dapat memantapkan ilmu berkaitan fiqh taharah khususnya berkaitan dengan darah-darah wanita agar dapat membantu menyelesaikan kekeliruan yang timbul. Metod pengajaran dan pembelajaran (PdP) di sekolah dan universiti juga perlu dinilai agar penyampaian lebih berkesan dan mudah difahami (https://worldconferences. net/proceedings/icasic2016). Justeru, objektif kajian ini adalah bertepatan dengan masalah kajian yang didapati dan sebagai kajian lanjutan kepada cadangan yang dikemukakan dalam kajian tersebut.

\section{TINJAUAN LITERATUR}

Kajian tentang Kefahaman Pelajar Terhadap Fiqh Thaharah (Permasalahan Darah Wanita): Tinjauan Di Uitm Cawangan Perlis, menjadi kesinambungan kepada kajian yang dijalankan ini. Dalam kajian tersebut dicadangkan agar menerapkan ilmu darah wanita dalam bidang pendidikan Islam samaada diperingkat sekolah atau universiti. Justeru, kajian ini adalah untuk menganalisis sejauhmana proses pengajaran dan pembelajaran tentang darah wanita dalam kurikulum pendidikan Islam di peringkat rendah dan menengah yang melibatkan bidang ibadat. Tindakan yang diambil oleh pihak tertentu daripada kajian ini mampu merubah tahap pemahaman masyarakat tentang ilmu darah wanita seawal usia baligh ekoran penerapan ilmu darah wanita dalam kurikulum pendidikan di sekolah rendah atau menengah lagi.

\section{METODOLOGI}

Metodologi kajian pula adalah kaedah kepustakaan dengan menganalisis kandungan buku teks pendidikan Islam rendah dan menengah, teks kelasik dalam bidang fiqh, tafsir, hadis dan bahasa. Selain itu, kaedah pemerhatian kefahaman peserta kelas belia dan dewasa pengajian darah wanita diukur berasaskan soalan yang diajukan tentang status darah wanita. Kajian dijalankan dengan menganalisis kandungan 
silibus pengajaran dan pembelajaran (P\&P) bagi Kurikulum Bersepadu Sekolah Menengah (KBSM) dan Kurikulum Standard Sekolah Rendah (KSSR) bagi buku pelajaran pendidikan Islam tahun 3,4,5 dan 6. Manakala bagi peringkat menengah pula analisis dilakukan terhadap sukatan pembelajaran bagi buku tingkatan 1 hingga 5 yang digunakan di Malaysia.

\section{DAPATAN}

Analisis Perbincangan Fiqh Dalam Kurikulum Rendah Dan Menengah

Kurikulum Peringkat Rendah

\begin{tabular}{|c|c|c|c|}
\hline Bil & $\begin{array}{c}\text { Nama Buku \& } \\
\text { Tajuk }\end{array}$ & $\begin{array}{c}\text { Sub Tajuk } \\
\text { Bidang Fiqh }\end{array}$ & Analisis \\
\hline 1 & $\begin{array}{l}\text { Pendidikan Islam } \\
\text { Tahun } 3 \\
\text { 1- bidang al-quran } \\
\text { (tilawah, hafazan, } \\
\text { kefahaman) } \\
\text { 2- bidang hadis } \\
\text { 3- bidang jawi } \\
\text { 4- bidang aqidah } \\
\text { 5- (Bidang Ibadah) } \\
\text { 6- Bidang sirah } \\
\text { 7- Bidang Adab }\end{array}$ & 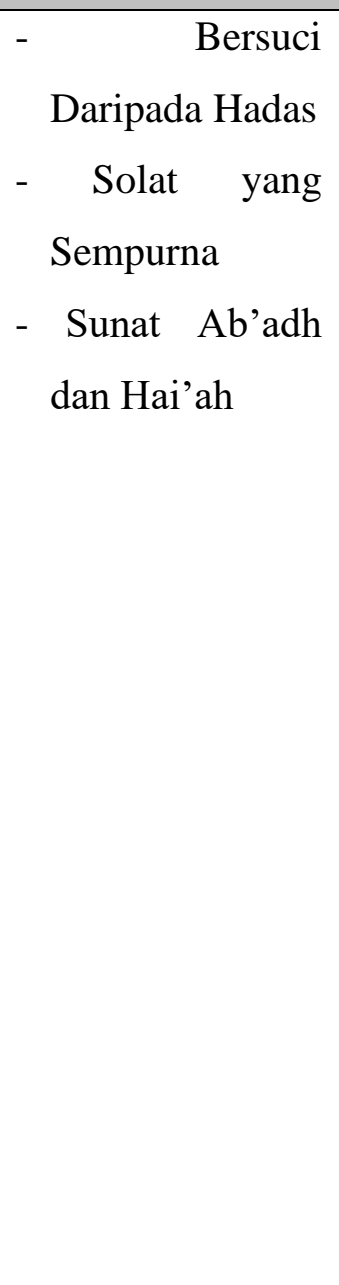 & $\begin{array}{l}\text { Pembelajaran berkenaan bersuci } \\
\text { daripada hadas, membincangkan tentang } \\
\text { maksud hadas, pembahagian hadas, } \\
\text { hukum bersuci daripada hadas, sebab } \\
\text { berhadas besar, kaedah bersuci daripada } \\
\text { hadas besar. Kajian mendapati buku } \\
\text { Pendidikan Islam tahun tiga menyebut } \\
\text { haid, nifas dan wiladah sebagai sebab } \\
\text { berhadas besar. Tiada perincian hukum } \\
\text { hakam berkenaan konotasi haid, nifas } \\
\text { dan wiladah kecuali dicatat pada ruangan } \\
\text { "info" definisi wiladah, nifas dan haid. } \\
\text { Manakala pada sudut Minda Bestari iaitu } \\
\text { sudut uji minda, ditanya soalan berikut: “ } \\
\text { Aminah telah mengalami haid selama } \\
\text { beberapa hari”. Bincangkan apakah yang } \\
\text { perlu Aminah lakukan semasa haid dan } \\
\text { selepas haid. }\end{array}$ \\
\hline 2 & $\begin{array}{l}\text { Pendidikan Islam } \\
\text { Tahun } 4 \\
\text { 1- bidang al-quran } \\
\text { 2- bidang hadis }\end{array}$ & $\begin{array}{l}\text { - } \\
\text { Kebersihan } \\
\text { Tuntutan Islam } \\
-\quad \text { Sucikanlah } \\
\text { dirimu }\end{array}$ & $\begin{array}{l}\text { Analisis terhadap kandungan pengajaran } \\
\text { dan pembelajaran bagi buku pendidikan } \\
\text { Islam tahun } 4 \text { didapati isu darah wanita } \\
\text { boleh diterapkan pembelajarannya di }\end{array}$ \\
\hline
\end{tabular}


Siti Fatimah Binti Salleh, dkk-Analisis Pendidikan Darah...

\begin{tabular}{|c|c|c|c|}
\hline & $\begin{array}{l}\text { 3- bidang jawi } \\
\text { 4- bidang aqidah } \\
\text { 5- (Bidang Ibadah) } \\
\text { 6- Bidang sirah } \\
\text { 7- Bidang Adab }\end{array}$ & $\begin{array}{l}\text { - Rukun Solat } \\
\text { - Aurat dalam } \\
\text { kehidupan }\end{array}$ & $\begin{array}{l}\text { bawah pecahan tajuk kebersihan tuntutan } \\
\text { Islam dan tajuk sucikanlah dirimu. } \\
\text { Pengkaji menyelusuri isu-isu yang } \\
\text { dibincangkan di bawah tajuk ini iaitu } \\
\text { tentang jenis-jenis najis dan cara } \\
\text { menyucikannya. Manakala di bawah } \\
\text { tajuk sucikanlah dirimu di bawah topik } \\
\text { perbincangan tentang erti mandi wajib, } \\
\text { sebab-sebab mandi wajib, perkara yang } \\
\text { dilarang ketika berhadas besar, rukun } \\
\text { mandi wajib, cara-cara mandi wajib. } \\
\text { Dinyatakan di bawah skop pembelajaran } \\
\text { ini haid, wiladah dan nifas sebagai } \\
\text { penyebab mandi wajib. Begitu juga } \\
\text { dinyatakan perkara-perkara yang } \\
\text { dilarang ketika berhadas besar ialah } \\
\text { mendirikan solat, mengerjakan tawaf, } \\
\text { duduk di dalam masjid. Kajian } \\
\text { mendapati perincian larangan ketika } \\
\text { berhadas besar dinyatakan secara umum } \\
\text { yang mana tidak mampu memberi } \\
\text { pencerahan hukum fiqh darah wanita } \\
\text { dalam sesi pembelajaran bagi tajuk ini. }\end{array}$ \\
\hline 3 & $\begin{array}{l}\text { Pendidikan Islam } \\
\text { Tahun } 5 \\
\text { 1- bidang al-quran } \\
\text { 2- bidang hadis } \\
\text { 3- bidang jawi } \\
\text { 4- bidang aqidah } \\
\text { 5- (Bidang Ibadah) } \\
\text { 6- Bidang sirah } \\
\text { 7- Bidang Adab }\end{array}$ & $\begin{array}{l}\text { - Tayammum } \\
\text { - Sunat ab'adh } \\
\text { dan sunat hai'ah } \\
\text { - Seruan azan } \\
\text { - Iqamat } \\
\text { - Solat berjemaah } \\
\text { - Kefarduan solat } \\
\text { Jumaat }\end{array}$ & $\begin{array}{l}\text { Dalam tajuk tayammum, kajian } \\
\text { mendapati tiada perbincangan yang } \\
\text { melibatkan darah wanita dalam sukatan } \\
\text { pengajaran dan pembelajaran bagi } \\
\text { pelajar tahun } 5 .\end{array}$ \\
\hline
\end{tabular}




\begin{tabular}{|c|c|c|c|}
\hline 4 & $\begin{array}{l}\text { Pendidikan Islam } \\
\text { Tahun } 6 \\
\text { 1- bidang al-quran } \\
\text { 2- bidang hadis } \\
\text { 3- bidang jawi } \\
\text { 4- bidang aqidah } \\
\text { 5- (Bidang Ibadah) } \\
\text { 6- Bidang sirah } \\
\text { 7- Bidang Adab }\end{array}$ & $\begin{array}{l}\text { - Ibadat puasa } \\
\text { pada bulan } \\
\text { ramadhan } \\
\text { - Solat sunat dua } \\
\text { hari raya } \\
\text { - Solatlah } \\
\text { sebelum kamu } \\
\text { disolatkan }\end{array}$ & $\begin{array}{l}\text { Kajian mendapati sukatan pengajaran } \\
\text { dan pembelajaran bagi pelajar tahun } 6 \\
\text { ditekankan topik p\&p berkenaan dengan } \\
\text { puasa iaitu tentang pengertian puasa, } \\
\text { hukum, dalil naqli puasa, syarat-syarat } \\
\text { wajib puasa, rukun puasa, sunat puasa, } \\
\text { syarat-syarat sah puasa, perkara-perkara } \\
\text { yang membatalkan puasa, hikmah puasa. } \\
\text { Perbincangan yang melibatkan } \\
\text { pembelajaran darah wanita hanya } \\
\text { didapati di bawah permasaalahan syarat- } \\
\text { syarat sah puasa dan perkara-perkara } \\
\text { yang membatalkan puasa iaitu suci } \\
\text { daripada haid, nifas dan wiladah. Disebut } \\
\text { juga haid, nifas dan wiladah merupakan } \\
\text { perkara yang membatalkan puasa. Di } \\
\text { dalam silibus ini hanya menyebut } \\
\text { konotasi haid, nifas dan wiladah tanpa } \\
\text { dikemukakan pendetailan hukum } \\
\text { hakamnya. }\end{array}$ \\
\hline
\end{tabular}

Kurikulum Peringkat Menengah (KBSM)

\begin{tabular}{|c|c|c|c|}
\hline Bil & $\begin{array}{ccc}\text { Nama } & \text { Buku } \& \\
\text { Tajuk } & & \end{array}$ & Sub Tajuk Bidang Fiqh & Ulasan \\
\hline 1 & $\begin{array}{l}\text { Pendidikan Islam } \\
\text { Tingkatan } 1 \\
\text { 1. Bahagian } \\
\text { Tilawah al-Quran } \\
\text { 2. Bahagian Hadis } \\
\text { 3. Bahagian Aqidah } \\
\text { 4. Bahagian Ibadat }\end{array}$ & $\begin{array}{l}\text { 4.1. Fardhu Ain dan Fardhu } \\
\text { Kifayah } \\
\text { - Konsep dan kepentingan } \\
\text { fardu ain dan fardu kifayah } \\
\text { 4.2. Bersuci Asas } \\
\text { Kebersihan } \\
\text { 4.2.1Konsep Bersuci, }\end{array}$ & $\begin{array}{l}\text { Isu bersuci yang disentuh dalam } \\
\text { silibus pembelajaran } \\
\text { memfokuskan kepada isu bersuci } \\
\text { yang melibatkan kebersihan } \\
\text { persekitaran bukan kebersihan } \\
\text { yang melibatkan hadas besariaitu } \\
\text { antaranya haid. Kemudian } \\
\text { dinyatakan pula konsep bersuci }\end{array}$ \\
\hline
\end{tabular}




\begin{tabular}{|c|c|c|}
\hline $\begin{array}{l}\text { 5. Bahagian Sirah } \\
\text { Rasulullah s.a.w } \\
\text { 6. Bahagian Akhlak } \\
\text { Islamiah }\end{array}$ & $\begin{array}{l}\text { 4.2.2 bersuci daripada } \\
\text { najis, } 4.2 .3 \text { Istinjak, } \\
\text { 4.2.4 wudhuk, } \\
\text { 4.2.5 mandi, } \\
\text { 4.2.6 tayammum, samak, } \\
\text { hikmah bersuci dalam } \\
\text { kehidupan individu dan } \\
\text { masyarakat. } \\
\text { 3. Solat } \\
\text { - Solat fardhu, khusyuk } \\
\text { solat dan kesannya kepada } \\
\text { kehidupan mukmin, } \\
\text { tuntutan solat berjamaah. } \\
\text { 4. Solat jumaat. } \\
\text { - Konsep solat jumaat, } \\
\text { khutbah solat jumaat, } \\
\text { khutbah jumaat, adab } \\
\text { makmum solat jumaat. } \\
\text { 5- Solat sunat tahiyyatul } \\
\text { masjid dan solat sunat } \\
\text { rawatib. }\end{array}$ & $\begin{array}{l}\text { yang melibatkan najis } \\
\text { mukhaffafah, mutawassitah, } \\
\text { mughallazah. Begitu juga } \\
\text { pembelajaran tentang wudhuk, } \\
\text { tidak dinyatakan dalam } \\
\text { pembelajaran tentang wudhuk } \\
\text { bagi perempuan yang mengalami } \\
\text { darah fasad atau istihadhah. } \\
\text { Kajian mendapati, di bawah tajuk } \\
\text { bersuci asas kebersihan } \\
\text { dibincangkan isu mandi. Pecahan } \\
\text { tajuk bagi isu mandi, } \\
\text { dibincangkan pengertian mandi, } \\
\text { sebab-sebab wajib mandi, rukun } \\
\text { mandi wajib, perkara-perkara } \\
\text { sunat ketika mandi wajib, hikmah } \\
\text { mandi wajib, perkara yang haram } \\
\text { dilakukan ketika berhadas besar. } \\
\text { Kajian mendapati, perkataan haid } \\
\text { dan nifas wujud dalam } \\
\text { pembelajaran tentang sebab- } \\
\text { sebab mandi. Manakala definisi } \\
\text { haid nifas dan istihadhah sahaja } \\
\text { dimasukkan dalam sukatan } \\
\text { pembelajaran sebagai sisipan } \\
\text { iaitu di ruang "tahukah anda?", } \\
\text { tiada perbincangan pembelajaran }\end{array}$ \\
\hline
\end{tabular}




\begin{tabular}{|c|c|c|c|}
\hline & & & $\begin{array}{l}\text { dilakukan ketika berhadas besar } \\
\text { dengan mengemukakan larangan } \\
\text { umum bagi lelaki dan perempuan } \\
\text { ketika berhadas besar dan } \\
\text { larangan tambahan bagi } \\
\text { perempuan yang haid atau nifas. } \\
\text { Iaitu (i) puasa wajib atau sunat, } \\
\text { (ii) bergurau senda antara pusat } \\
\text { dan lutut bagi suami isteri, (iii) } \\
\text { melakukan persetubuhan. }\end{array}$ \\
\hline 2 & $\begin{array}{l}\text { Pendidikan Islam } \\
\text { Tingkatan } 2 \\
\text { 1. Tilawah al-Quran } \\
\text { 2. Hadis } \\
\text { 3. Akidah } \\
\text { 4. Ibadat } \\
\text { 5.Sirah dan } \\
\text { Tamadun Islam } \\
\text { 6. Adab dan Akhlak } \\
\text { Islamiah }\end{array}$ & $\begin{array}{l}\text { 1- Solat Qasar dan Jamak } \\
\text { 2- Puasa Menjana } \\
\text { keperibadian Muslim } \\
\text { 3- Ibadat Puasa } \\
\text { 4- Golongan Yang Harus } \\
\text { Berbuka Puasa } \\
\text { 5- Menghayati Bulan } \\
\text { Ramadhan } \\
\text { 6- Zakat Fitrah }\end{array}$ & $\begin{array}{l}\text { Di bawah sub topik ibadat puasa } \\
\text { dibincangkan topik-topik berikut, } \\
\text { iaitu taarif puasa, rukun puasa, } \\
\text { perkara yang membatalkan } \\
\text { puasa, syarat-syarat wajib puasa, } \\
\text { syarat-syarat sah puasa, perkara } \\
\text { sunat dalam ibadat puasa, perkara } \\
\text { makruh ketika berpuasa, jenis- } \\
\text { jenis puasa, hikmah berpuasa, } \\
\text { akibat buruk orang yang tidak } \\
\text { berpuasa. } \\
\text { Terdapat 10 tajuk kecil yang } \\
\text { dibincangkan dalam tajuk ibadat } \\
\text { puasa. Hanya dua perkataan } \\
\text { sahaja disebut } \\
\text { pembelajaran ini iaitu perkataan } \\
\text { haid dan nifas. Kajian mendapati } \\
\text { bahawa cakupan pembelajaran } \\
\text { secara terperinci atau secara asas } \\
\text { tentang darah wanita sukar } \\
\text { dilaksanakan melihat kepada } \\
\text { peruntukan masa P\&P dengan } \\
\text { peruntukan tajuk yang perlu }\end{array}$ \\
\hline
\end{tabular}




\begin{tabular}{|c|c|c|c|}
\hline & & & $\begin{array}{l}\text { dipelajari. Pelajar tidak mampu } \\
\text { memahami dan mendalami isu } \\
\text { darah wanita jika topik darah } \\
\text { wanita tidak dijadikan sebagai } \\
\text { sub topik berasingan dalam P\&P } \\
\text { bagi bab ibadah. }\end{array}$ \\
\hline 3 & $\begin{array}{l}\text { Pendidikan Islam } \\
\text { Tingkatan } 3 \\
\text { Tilawah al-Quran } \\
\text { Hadis } \\
\text { Akidah } \\
\text { Ibadat } \\
\text { Sirah dan Tamadun } \\
\text { Islam } \\
\text { Adab dan Akhlak } \\
\text { Islamiah }\end{array}$ & $\begin{array}{l}\text { 1- Solat ketika Sakit } \\
\text { 2- Solat Aidil fitri dan } \\
\text { Aidil Adha } \\
\text { 3- Solat Sunat Hajat } \\
\text { 4- Solat Sunat Tahajjud } \\
\text { 5- Pengurusan jenazah } \\
\text { Satu Kefardhuan } \\
\text { 6- Zakat Harta }\end{array}$ & $\begin{array}{l}\text { Tiada perbincangan dalam } \\
\text { bidang ibadat tentang isu darah } \\
\text { wanita dalam sesi pengajaran dan } \\
\text { pembelajaran. }\end{array}$ \\
\hline 4 & $\begin{array}{l}\text { Pendidikan } \\
\text { Syariah Islam } \\
\text { Tingkatan } 4 \\
\text { Aqidah } \\
\text { Usul Fiqh } \\
\text { Ayat Hukum } \\
\text { Hadis Hukum } \\
\text { Fiqh }\end{array}$ & $\begin{array}{l}\text { 1- Sejarah Ibadat Haji } \\
\text { 2- Manasik Haji } \\
\text { 3- Pelaksanaan Haji } \\
\text { 4- Niabah Haji } \\
\text { 5- Pengurusan Haji di } \\
\text { Malaysia } \\
\text { 6- Sembelihan } \\
\text { 7- Qurban } \\
\text { 8- Aqiqah } \\
\text { 9- Muamalat Dalam Islam } \\
\text { 10- Pengenalan Muamalat } \\
\text { Dalam Islam } 1 \\
\text { 11- Pengenalan Muamalat } \\
\text { Dalam Islam } 2\end{array}$ & $\begin{array}{l}\text { Tiada perbincangan dalam } \\
\text { bidang ibadat tentang isu darah } \\
\text { wanita dalam sesi pengajaran dan } \\
\text { pembelajaran samaada dalam } \\
\text { subtopik fiqh mahupun ayat dan } \\
\text { hadis hukum. }\end{array}$ \\
\hline 5 & $\begin{array}{l}\text { Pendidikan } \\
\text { Syariah Islam } \\
\text { Tingkatan } 5\end{array}$ & $\begin{array}{l}\text { 1- Perkahwinan } \\
\text { 2- Tanggungjawab Suami } \\
\text { Isteri }\end{array}$ & $\begin{array}{l}\text { Kesemua topik-topik yang } \\
\text { dibincangkan tidak didapati } \\
\text { cakupan tajuk pengajaran dan }\end{array}$ \\
\hline
\end{tabular}




\begin{tabular}{|l|l|l|l|}
\hline Aqidah & 3-Pembubran perkahwinan & pembelajaran yang berkait \\
Sejarah & 4- Nusyuz, Zihar dan & dengan darah wanita. \\
Perundangan Islam & Poligami & \\
Usul Fiqh & 5- Peranan Mahkamah & \\
Ayat-Ayat Hukum & Syar'iyyah Di Malaysia & \\
Hadis-Hadis & 6- Konsep Kehakiman & \\
Hukum & Dalam Islam & \\
Fiqh & 7- Jenayah Dalam Islam & \\
\hline
\end{tabular}

Kajian mendapati perbincangan tentang pendidikan darah wanita di dalam kurikulum standard sekolah rendah terkandung di dalam buku Pendidikan Islam tahun 3 (Muhammad Nasir bin Arshad et. al, 2018) dengan hanya wujud konotasinya sahaja iaitu haid, nifas dan wiladah. Manakala definisi haid, nifas dan wiladah dinyatakan pada ruangan "Info" iaitu satu ruangan tambahan yang mana ia tidak termasuk sebagai pecahan tajuk kecil kepada silibus pengajaran dan pembelajaran di bawah perkara ibadah.

Manakala bagi buku pendidikan Islam tahun 4 (Hasnah binti Yahya et. al, 2014) dan 6 (Nursuhana binti Abdullah et. al, 2015), terdapat konotasi haid nifas dan wiladah, ia hanya disebut secara tidak langsung di bawah perbincangan tajuk mandi wajib iaitu penyebab kepada mandi anataranya kerana haid, nifas dan wiladah, dan disebut secara umum larangan-larangan semasa berhadas besar tanpa mengkhususkan perbincangan larangan dalam pembelajaran tersebut sebagai larangan semasa haid. Begitu juga disebut secara tidak langsung konotasi haid, nifas dan wiladah di dalam buku pendidikan Islam tahun 6 dalam perbincangan perkara yang membatalkan puasa. Kajian mendapati pendedahan tentang pendidikan darah wanita tidak terdapat atau tidak dibincangkan dalam buku pelajaran pendidikan Islam tahun 5 (Nursuhana binti Abdullah et. al, 2014).

Bagi kurikulum bersepadu sekolah menengah pula yang melibatkan analisis buku pendidikan Islam tinkatan 1 hingga 5 , kajian mendapati buku pendidikan Islam tingkatan 1 dan 2 (Mohammad Nazmi bin Desa et. al, 2015; Razali bin Syarif et. al, 2014) menyebut perkataan haid dan nifas dalam pembelajaran tentang sebab-sebab mandi. Manakala definisi haid, nifas dan istihadhah dimasukkan dalam sukatan pembelajaran sebagai sisipan iaitu di ruang "tahukah anda?" dan buku tingkatan 2 pula menyebut konotasi haid dan nifas sahaja tanpa ada penjelasan definisi dan hukum. 
Analisis bagi buku pendidikan Islam tingkatan 3, 4 dan 5 tidak mendapati perbincangan tentang darah wanita (Aimi bin Hamzah et. al, 2011; Muhammad bin Arifin et.al, 2017 Rijaluddin bin Yahya et. al, 2016).

\section{PERBINCANGAN}

\section{Analisis skop pendidikan asas darah wanita}

Melihat kepada usia minimum yang disebut oleh fuqaha empat mazhab adalah 9 tahun hijrah atau hampir kepada 9 tahun hijri (al-Sarkhasi, 1989; Ibnu Abidin, t.th; alDardir, t.th; al-Dusuqi, t.th; al-Ramli, 1984; al-Sharbini, 2000; Ibn Qudamah, 2000; alkaf, 2003; Siti Fatimah, 2014) dengan mengambilkira secara normalnya kanakkanak perempuan pada usia tersebut sudah didatangi haid. Justeru, langkah mewujudkan pendidikan asas darah wanita dalam silibus pengajaran dan pembelajaran bagi pelajar tahun 3 adalah signifikan. Antara pendidikan awal darah wanita yang perlu difahami oleh pelajar tahun 3 sekurangkurangnya hukum atau penjelasan yang berkait dengan definisi haid, istihadhah, implikasi haid kepada baligh dan beban taklifan yang dipertanggungjawabkan, warna darah, tempoh minima dan maksima haid, tempoh minima dan maksima suci, ibadat yang dilarang semasa haid, mustahadhah mubtadaah mumayyizah dan ghairu mumayyizah, pengurusan solat perempuan istihadhah.

Usia se awal sembilan tahun merupakan usia yang signifikan didedahkan ilmu darah wanita mengambilkira usia awal haid bagi kanak-kanak perempuan adalah Sembilan tahun. Melalui proses pendidikan di sekolah, akan wujud keselarasan pemahaman secara terancang dan terurus. Hal ini mampu mengatasi masalah sosial dalam masyarakat yang belum diselaraskan tempoh dan tahap pembelajaran tentang darah wanita ini.

Realiti hari ini, pembelajaran tentang ilmu darah wanita adalah berorientasikan kepada alternatif sendiri oleh masyarakat yang dipandu oleh kesedaran. Sebagaimana diketahui, ilmu darah wanita merupakan ilmu yang dituntut untuk mempelajarinya oleh setiap mukallaf dan ia termasuk dalam kategori ilmu fardhu ain. Oleh yang demikian, menjadi kewajipan dan keutamaan ke atas kaum lelaki untuk mempelajari dan mendalami ilmu tentang darah wanita, melihat kepada beban yang akan dipertanggungjawabkan ke atas kaum lelaki iaitu mengajari anak-anak perempuan dan isteri mereka.

Oleh kerana tiada sukatan pembelajaran secara padu di dalam kurikulum pendidikan rendah dan menengah tentang darah wanita, antara cadangan kajian untuk pembelajaran ilmu darah wanita ialah dengan mewujudkan aktiviti kerohanian melalui penganjuran 
ceramah, forum, diskusi, kursus secara bersiri bagi memberi pendidikan awal dan asas tentang darah wanita kepada para pelajar di peringkat rendah dan menengah. Pihak sekolah juga berperanan menganjurkan aktiviti tahunan seperti seminar asas ambang baligh dengan kolaborasi antara pihak luar seperti pejabat agama atau institusi mufti negeri.

Tajuk perbincangan tentang darah wanita perlu dijadikan tajuk berasingan bukan secara sisipan dalam kurikulum pendidikan Islam di peringkat rendah atau menengah. Justifikasinya adalah merujuk kepada kitab-kitab muktabar dalam mazhab empat menjadikan topik haid nifas dan istihadhah sebagai topik yang khusus dengan perbincangan yang luas dan padat iaitu bukan secara serapan di bawah tajuk-tajuk tertentu, kecuali perbincangan yang berkaitan. Antara kitab turath yang membincangkan tentang darah wanita seperti Majmu 'ah Rasa'il Ibnu 'Abidin oleh Muhammad Amin Afandi Ibnu Abidin sebanyak 51ms, Bada 'i' al-Sana 'i' fi tartib al-Shara ' $i$ ' oleh 'Ala'uddin Abu Bakar bin Mas‘ud al-Kasani sebanyak 12ms, alMabsut oleh Shamsuddin al-Sarkhasi sebanyak 85ms, al-Hidayah Syarah Bidayah al-Mubtadi oleh al-Marghinani sebanyak 5ms, al-Fatawa al-Hindiyyah sebanyak 6ms,al-Llibab fi Sharh al-Kitab oleh alSyaikh 'Abd al-Ghani al-Ghanimi sebanyak 8ms, Syarh Fath al-Qadir oleh Ibn alHumam sebanyak 30ms, al-Sharhu alSaghir ala Aqrab al-Masalik ila Mazhab alImam Malik, oleh Abu al-Barakat Ahmad bin Muhammad al-Dardir sebanyak $11 \mathrm{~ms}$, Hasyiah al-Dusuqi ala al-Syarh al-Kabir oleh Shamsuddin al-Shaikh Muhammad alDusuqi sebanyak 9ms, al-Bayan fi Fiqh alImam al-Syafi'I oleh al-'Umrani sebanyak 86ms, Mughni al-Muhtaj Ila Ma'rifah Ma'ani Alfaz al-Minhaj oleh AlShamsuddin Muhammad bin Muhammad alKhatib al-Shirbini sebanyak 19ms-, Fathu al-Jawad bi Sharh al-Irshad oleh Ibn hajar al-Haitami al-Makki al-Syafi'I sebanyak 19 ms, al-Hawi al-Kabir oleh Abu al-Hasan Ali bin Muhammad bin Habib al-Mawardi sebanyak 68ms, al-Mughni oleh Ibn Qudamah al-Maqdisi sebanyak 68, Sharah al-Zarkasyi oleh Muhammad al-Zarkashi sebanyak 20ms, al-Mubdi' Sharh al-Muqni' oleh Ibn Muflih sebanyak 38ms.

Justeru, menjadi kewajaran dijadikan topik darah wanita ini sebagai satu subtopik berasingan dalam kurikulum sekolah samaada di peringkat rendah atau menengah kerana ia merupakan satu ilmu yang penting dan perlu diberi pendedahan di peringkat awal usia baligh.

Selain itu, penubuhan kelab wanita sebagai salah satu aktiviti kokurikulum di peringkat rendah dan menengah seperti tunas puteri atau diserapkan pendidikan 
darah wanita dalam aktiviti kokurikulum pandu puteri. Justifikasinya adalah ilmu darah wanita merupakan ilmu yang wajib dan mesti dipelajari dan difahami seawal usia baligh, diadaptasi apabila mencecah usia baligh. Ia juga menjadi penting kerana implikasi darah wanita mempunyai impak kritikal terhadap kesahan ibadat yang melibatkan taharah, solat, puasa, bacaan, sentuhan dan bawa al-Quran, memasuki masjid dengan tujuan iktikaf atau sebaliknya. Seterusnya ibadat umrah atau haji dan beberapa tuntutan syarak yang berkait dengan status darah wanita. Pendidikan darah wanita penting kerana ia melibatkan tenggungjawab mukallaf dengan dalam memenuhi tuntutan syarak iaitu hak Pencipta.

Pihak Kementerian Pendidikan Malaysia di bawah kluster pendidikan Islam atau Bahagian Pendidikan Islam (BPI) (https:// www.moe.gov.my) dicadangkan agar menilai semula silibus pendidikan Islam bagi tajuk ibadat agar dimasukkan ilmu tentang darah wanita dalam silibus P\&P dalam kurikulum pendidikan Islam mengikut kesesuaian usia awal baligh kanak-kanak dan siri pemantapan juga wajar dimasukkan ke dalam silibus P\&P di peringkat menengah. Ilmu darah wanita wajib dipelajari oleh semua pelajar baik perempuan mahupun lelaki. Justifikasinya adalah tuntutan utama pembelajaran ilmu fardhu ain, yang salah satunya termasuk ilmu darah wanita adalah ditaklifkan ke atas kaum lelaki kerana seorang lelaki akan berubah status beban taklif kepada seorang suami atau bapa yang wajib ke atasnya mengajar isteri atau anak perempuannya. Justeru, penerapan ilmu darah wanita ke dalam kurikulum sekolah samaada diperingkat rendah atau menengah sangat relevan tanpa memikirkan isu gender. Kejelasan kaedah penentuan darah mapu mengharmonikan hubungan kesahan ibadat seorang hamba dengan pencipta dan ibadat adalah ilmu asas yang perlu dimantapkan oleh seorang mukallaf di samping ilmu-ilmu lain.

\section{KESIMPULAN}

Kajian mendapati pendidikan tentang darah wanita dalam pengajaran dan pembelajaran (P\&P) bagi Kurikulum Bersepadu Sekolah Menengah (KBSM) dan Kurikulum Standard Sekolah Rendah (KSSR) bagi buku pelajaran pendidikan Islam di Malaysia hanya memfokuskan kepada konotasi haid, nifas, istihadhah dan wiladah. Perbincangan tentang laranganlarangan bagi orang yang berhadas dibincang secara sisipan dalam topik puasa dan mandi wajib. Ia tidak dibincang dalam satu topik yang berasingan.

Keterbatasan ruang pendidikan darah wanita menjadi justifikasi keperluan 
mewujudkan pengajaran dan pembelajaran ke dalam buku teks sekolah rendah dan menengah dengan topik berasingan melihat kepada permasalahan ini bersifat menyeluruh, yang dilalui secara normalnya oleh kaum perempuan dan ia juga turut wajib dipelajari oleh kaum lelaki ekoran beban tanggungjawab yang akan dipikul sebagai suami, bapa dan guru.

Aspek proses pembelajaran menjadi wajib dan fardu ain kerana ia berkaitan dengan kesahan ibadat seseorang individu mukallaf. Tanggungjawab memastikan pemerkasaan terhadap pendidikan darah wanita dalam kurikulum sekolah menengah dan rendah di Malaysia ini, seharusnya dipandang serius dan diusahakan bersama oleh kementerian dan pihak-pihak yang berkaitan.

\section{PENGHARGAAN}

Terima kasih kepada Universiti Sultan Zainal Abidin (UniSZA) di atas segala sokongan yang diberikan di bawah Dana Penyelidikan Universiti (DPU) 2017 yang bertajuk "Penentuan Katogori Darah Wanita Menurut Pakar Perubatan dalam Penyelesaian Perselisihan Hukum Fiqh" [UniSZA/ 2017/DPU/24], yang dikendalikan oleh penyelidik dari Fakulti Pengajian Kontemporari Islam.

\section{RUJUKAN}

Aimi bin Hamzah et. al, 2011, Pendidikan Syariah Islamiah Tingkatan 5, Kementerian Pendidikan Malaysia, Dewan bahasa Dan Pustaka: Malaysia.

Al-Dardir, Abu al-Barakat Ahmad bin Muhammad, al-Sharhu al-Saghir ala Aqrab al-Masalik ila Mazhab al-Imam Malik, t.tp: Dar Ma'arif.

Al-Dardir, Abu al-Barakat Ahmad bin Muhammad, t.th, al-Sharhu al-Saghir ala Aqrab al-Masalik ila Mazhab alImam Malik, t.tp: Dar Ma’arif.

Al-Dusuqi, Shamsuddin al-Shaikh Muhammad, t.th, Hasyiah al-Dusuqi ala alSyarh al-Kabir, t.tp: Dar Ihya' al-Kutub al-'Arabiyyah.

Al-Dusuqi, Shamsuddin al-Shaikh Muhammad, t.th, Hasyiah al-Dusuqi ala alSyarh al-Kabir, t.tp: Dar Ihya' al-Kutub al-'Arabiyyah.

Al-Ghanimi, al-Syaikh 'Abd al-Ghani, 1993, al-Llibab fi Sharh al-Kitab, Lubnan: Maktabah al-'Ilmiyyah.

Al-kaf, hasan bin Ahmad bin Muhammad bin Salim, 2003, al-Taqrirat al-Sadidat fi al-masa'il al-Mufidah, Yaman: Dar al-'Ilm wa al-Dakwah.

Al-Kasani, 'Ala'uddin Abu Bakar bin Mas'ud, 2000, Bada' $i$ ' al-Sana ' $i$ ' $f i$ 
tartib al-Shara ' $i$ ', Lubnan: Dar Ihya' alTurath al-'Arabi.

Al-Marghinani, Burhanuddin Abi al-Hasan Ali bin Abi Bakr bin Abdul Jalil alRushdani, al-Hidayah Syarah Bidayah al-Mubtadi, Lubnan: Dar al-Kutub al'Ilmiyyah.

Al-Mawardi,Abu al-Hasan Ali bin Muhammad bin Habib, 1994, al-Hawi al-Kabir, Lubnan: Dar al-Kutub al-'Ilmiyyah.

Al-Ramli, Shamsuddin Muhammad bin Abi al-'Abbas Ahmad bin Hamzah Ibn Shihab, 1984, Nihayah al-Muhtaj ila Syarh al-Minhaj, Lubnan: Dar al-Fikr.

Al-Sarkhasi, Shamsuddin, 1989, al-Mabsut, Lubnan: Dar al-Ma'rifah.

Al-Shirbini, Shamsuddin Muhammad bin Muhammad al-Khatib, 2000, Mughni al-Muhtaj Ila Ma 'rifah Ma'ani Alfaz alMinhaj, Lubnan: Dar al-Kutub alIlmiyyah.

Al-Zarkashi, Muhammad bin Abdullah bin Muhammad, 2002, Sharah al-Zarkasyi, Lubnan: Dar al-Kutub al-'Ilmiyyah.

Hasnah binti Yahya et. al, 2014, Pendidikan Islam Tahun 4, Kementerian Pendidikan Malaysia, Dewan bahasa Dan Pustaka: Malaysia.

Ibn al-Humam, Kamaluddin bin Muhammad bin 'Abd al-Wahid, t.th, Syarh Fath alQadir, Lubnan: Dar al-Fikr.
Ibn Muflih, Burhanuddin Abu Ishaq Ibrahim bin Muhammad, 2003, al-Mubdi' Sharh al-Muqni', al-Sa'udiyyah: Dar 'Alim alKutub.

Ibn Qudamah, al-Maqdisi, 2004, al-Mughni, tahqiq: Muhammad Sharif al-Din Khattab, Qaherah: Dar al-Hadis.

Ibnu Abidin, Muhammad Amin Afandi, t.th, Majmu'ah Rasa'il Ibnu 'Abidin, Lubnan: Dar Ihya' al-turath al-'Arabi.

Ibnu Abidin, Muhammad Amin Afandi, t.th, Majmu'ah Rasa'il Ibnu 'Abidin, Lubnan: Dar Ihya' al-Turath al-'Arabi.

Mohammad Nazmi bin Desa et. al, 2015, Pendidikan Islam Tingkatan 2, Kementerian Pendidikan Malaysia, Dewan bahasa Dan Pustaka: Malaysia.

Muhammad bin Arifin et.al, 2017, Pendidikan Syariah Islamiah Tingkatan 4, Kementerian Pendidikan Malaysia, Dewan bahasa Dan Pustaka: Malaysia.

Muhammad Nasir bin Arshad et. al, 2018, Pendidikan Islam Tahun 3, Kementerian Pendidikan Malaysia, Dewan bahasa Dan Pustaka: Malaysia.

Nursuhana binti Abdullah et. al, 2014, Pendidikan Islam Tahun 5, Kementerian Pendidikan Malaysia, Dewan bahasa Dan Pustaka: Malaysia. Nursuhana binti Abdullah et. al, 2015, Pendidikan Islam Tahun 6, 
Kementerian Pendidikan Malaysia,

Dewan bahasa Dan Pustaka: Malaysia.

Razali bin Syarif et. al, 2014, Pendidikan

Islam Tingkatan 1, Kementerian Pendidikan Malaysia, Dewan bahasa Dan Pustaka: Malaysia.

Rijaluddin bin Yahya et. al, 2016, Pendidikan Islam Tingkatan 3, Kementerian Pendidikan Malaysia, Dewan bahasa Dan Pustaka: Malaysia.

Siti Fatimah Salleh, 2014, al-'A'zar alKhassah bi al-Nisa' wa Ahkamuha fi alIbadat: Dirasah Fiqhiyyah Muqaranah, Jordan: Dar al-Nafaes.

https://worldconferences.net/proceedings/ic asic2016/fullpaper/malay\%20papers/IC
\%20151\%20KEFAHAMAN\%20PELA JAR\%20TERHADAP\%20FIQH\%20T

HAHARAH.pdf, dilayari pada 14/5/2019, Selasa jam 11.00 pagi.

https://www.moe.gov.my/index.php/korpor at-menu/organisasi/bahagian-danunit/3525-bahagian-pendidikan-islam, dilayari pada 10/6/2019, Isnin jam 10.00 pagi. 